\title{
Social Organization and Mating System of Macaca Fascicularis (Long Tailed Macaques)
}

\author{
Karimullah (Correspondence author) \\ M01-10-02 Restu Universiti Sains Malaysia \\ Pulau Pinang, Malaysia \\ Tel: 60-17-410-5298Ｅ-mail: karimullah76@yahoo.com \\ Shahrul Anuar \\ School of Biological Sciences, Universiti Sains Malaysia \\ Pulau Pinang, Malaysia
}

Received: December 01, 2010 Accepted: December 14, 2010 doi:10.5539/ijb.v3n2p23

\begin{abstract}
Long tailed macaques (Macaca fascicularis) are organized into multi-male/multi-female groups have a strong hierarchical ties with each others. The data collected in present study was random and continuous sampling data. It was depicted from present study that the alpha male exhibit significant dominance for the behaviour of fighting $(p<0.05)$, eating $(p<0.05)$ and grooming (received) $(p<0.05)$. Other behaviours grooming (given), attacking and protection were observed higher in beta male. Furthermore, the male and female social relationships were also assessed and compared to the other members of the group. The behaviors of males was found significant for the aggression $(\mathrm{p}<0.028)$, approach $(\mathrm{p}<0.002)$ and reconciliation $(\mathrm{p}<0.01)$, while observed significant difference in the behavior of grooming $(p<0.012)$, biting $(p<0.016)$, sex $(p<0.031)$, submission $(\mathrm{p}<0.004)$ and baby care $(\mathrm{p}<0.01)$ in females respectively. It is concluded that the Macaca fascicularis bound in hierarchical system and mating structure showed that the male and female mate with multiple partners suggesting that mating is composed on polyandry and polygamy.
\end{abstract}

Keywords: Macaca fascicularis, Social behaviors, Mating system

\section{Introduction}

Regarding with the social organization of Macaca fascicularis Van Noordwijk (1993) described that primate social life is highly complex. They should maintain relationships with other individuals, as well as keep track of dyadic relations within the group. They have to recognize the rank of conspecifics and act accordingly (Nobuyuki, 2010). They must recognize adversaries and make decisions about which individuals to form alliances with. Furthermore, primates exploit social knowledge from the individuals they interact with. In order for primates to manage life in such complex social environments, social skills have got to be acquired and utilized (Janson \& van Schaik, 1993). All species of macaques have a multimale, multifemale social organization and a promiscuous mating system in which both males and females generally mate with multiple partners (Soltis, 2001). Despite the knowledge of general aspects of mating behavior in the macaque, information on how mating activity is distributed throughout the female menstrual cycle and to what extent it is temporally related to the timing of ovulation and the female fertile phase does not exist. Although all anthropoid primate species, including macaques, can copulate at any stage of the ovarian cycle, Dominance style depends on the gradient of the hierarchy (Dixson, 1998): despotism signifies that the dominance hierarchy is precipitous. Furthermore, in primates, particularly of the genus macaques, these societies differ in a number of other characteristics: in despotic societies aggression is more unidirectional, social behavior is correlated more strongly with dominance, grouping is less cohesive mate choice is more selective, and male migration is more frequent (Thierry, 1990). Whereas each of these differences between related species is usually explained as a separate adaptation shaped by individual selection. An attempt to understand the evolution and maintenance of this system, we focus on those aspects of macaques social organization that are conservative and shared by many, In doing so, it is not trying to minimize the importance of variation and flexibility in the social organization of primates. But to define 
a complex mating and rearing system and the underlying structure upon which such variation is built. In addition, it also examines the mating strategies of Macaca fascicularis, patterns of dominance, and affiliation among individuals and at the end with an effort at combination using the threat of predation and food distribution as the main causal factors of social systems.

\section{Materials and Methods}

\subsection{Study area and Subject}

Penang Botanical Gardens was selected as study area. It is situated eight kilometers off the north-western coast of Peninsular Malaysia. Georgetown, the capital of Pinang. The Botanical Gardens is very famous, it gives out plant resources and it is the main center for the protection of wild species (Heywood, 1991). The study was carried out only on Macaca fascicularis Spp. because this specie has various behaviours and activities and easily available as compared to other primates.

\subsection{Field Method and Population Study}

The method of observation in the Botanical Gardens used in this study was quite slow; because, it involves gentle walking and waiting in different corners of the forest. Maximum time was spent waiting outside the jungle for the troop to appear, because of the dense flora and noisy, difficult to access monkeys like in open spaces (i.e. walks on open grounds or tall trees standing alone). Another procedure used was to stay and wait for a long time near the fruiting trees and location where food was available for them. This method usually requires more time for observer to walk around in the whole Gardens. The observer took all observations, though occasionally information was provided by other sources either gardeners or visitors regarding the presence of troops elsewhere in the Gardens (Heymann et al. 2002), (Oommen and Shanker, 2008) and (Pruetz and Leasor, 2002). This study took five months from February to June 2007, and most of the fieldwork was done in the morning from 09:00 to 12:00 hours and in the evening from 14:00 to 17:00 hours. After 17.00 hours the troops would be heading their way back towards the forest. Each behavior was observed from each group kept under observation for 60 second and the data was collected for the following behaviors:

\subsection{Behaviors studied}

Aggression: Fight, bite and hit (Izard and Smith 2000).

Approach: Decreasing the distance to less than 0.6 meter (Gray 1986).

Baby care: Protecting and nursing a baby (Nozaki 2009).

Biting: Wound received either by own or by other animal (Thierry 1986).

Conciliation: Affiliative contact from aggressee to aggressor (Aureli 1992).

Eating: Eating from clumped food sources (mainly fruit). Handling and eating dispersed food items (often insects) (Van Schaik et al. 1983).

Fighting: Making loud sounds and showing crazy behaviours. Aggressive interactions between individuals or groups were usually accompanied by loud vocalizations. Fighting, biting and hitting (Izard and Smith 2000).

Facial threat: Lipsmacking, scalp lifting, showing face (Marjolijn et al. 1998).

Grooming (given or received): Cleaning the body, one monkey picks through the hair of another (Izard and Smith 2000).

Moving: When an object changed its position by walking (Van Schaik et al. 1983).

Protection: Defense against external aggression (David 1986).

Reconciliation: A friendly reunion between former opponents (Filippo 1997).

Sex: Mounting, inspection and copulation (Izard and Smith 2000)

Shaking branches: Hanging on and movement on branches

Submission: Grimacing and lipsmacking (Bernstein 1974).

\subsection{Statistical analysis}

The statistical package 'SPSS' version 16 was used to test the statistical significance of some of the findings of which the significant value for the findings must be less than $0.05(\mathrm{p}<0.05)$. One Way ANOVA test was used to find the difference among behaviours which was related with the different activities of Macaca fascicularis. T-test was used to compare the dominance style of Macaca fascicularis.

\section{Results}

\subsection{Group Organization}

Total of five subsequent groups were observed during the study. These groups were based on dominance, subgroups members and sub-ordinates. The dominance members were found in the centre of the groups, 
subgroups members in the middle and sub-ordinates at the periphery of the groups. This composition was found during food site. In other circumstance i.e. moving or threats the dominance were found at front following by sub-ordinates and the sub groups members respectively.(Figure, 1).

\subsection{Dominance behaviors}

A comparison of dominant behaviors of the Macaca fascicularis between the alpha and beta males was carried out. For the dominant behaviors the frequencies were recorded, their means and standard deviations were calculated. The p-values were also calculated for each of the behavior.

\subsection{Dominance behaviors of alpha and beta male}

In terms of fighting the alpha male showed significant $(\mathrm{p}<0.05)$ dominance and a higher mean 2.23 as compared to the beta male. Sexual behaviors was found non-significant $(\mathrm{p}=0.74)$ and a higher mean of 1.29 was observed for the alpha male. Eating was evaluated to be significantly higher $(\mathrm{p}<0.01)$ in alpha male with a mean of 2.03 in comparison of beta male. Shaking of branches behavior was noted non-significant $(\mathrm{p}=0.96)$ and higher in the alpha male with a mean of 1.91 . While, moving behavior was found non-significantly $(\mathrm{p}=0.536)$ and higher in the beta male with a mean of 1.83 . Grooming received was analyzed to be significantly $(\mathrm{p}<0.01)$ higher in alpha male with mean of 0.91 . While Grooming given was observed non-significantly higher $(p=0.051)$ in the beta male with a mean of 2 . Attacking behavior was significantly $(\mathrm{p}<0.05)$ higher in beta male with a mean of 2.17 . Protection was non-significantly higher in the beta male with a mean of 2.72 . Further Facial threat was non-significantly $(\mathrm{p}=0.27)$ higher in the alpha male with a mean of 1.06 . The details are illustrated in Table 1 .

\subsection{Male social relationship}

The social relationship of the male with different members of the group was estimated. The relationships were among male-female, male-male, male-juvenile and male-infant, the behaviors studied were grooming, aggression, submission, approach and reconciliation. Grooming was estimated to be non-significant higher $(\mathrm{p}=0.50)$ and the mean for the male-male was found to be $2.07,1.71$ for male-juvenile, 1.40 for male-infant and 1.25 for male-female. Aggression found significant $(\mathrm{p}<0.05)$, aggression was observed higher in male-infant with mean 3.30 followed by male-juvenile 2.64, male-male 2.40 and male-female 1.88 . Submission calculated to be non-significantly higher $(\mathrm{p}=0.41)$; the mean was 2.53 in male-male followed by male-female 2.38 , male-juvenile 2.36 and male-infant 1.40. Approach estimated to be significantly $(\mathrm{p}<0.01)$ higher, in male-male with the mean value 4.73 followed by male-infant 3.90, male-juvenile 4.15 and male-female 2.75 . Reconciliation was evaluated to be significantly higher $(\mathrm{p}<0.05)$ in male-female with a mean of 6.75 followed by male-juvenile 5.07 , male-infant 5 and male-male 3.27 (Table 2).

\subsection{Female dominance style and social relationship}

Dominance in terms of behaviors is also exhibited by females with respect to other members in the group, aggression was found to be non-significance $(p=0.23)$ higher, the highest mean 2.3 was observed in female-juvenile followed by female-female 2.1, female-infant 1.75 and female-male 1.27 . Grooming evaluated significance $(p<0.05)$ higher in dominance female, the mean for the female and infant was found to be the highest 3.75, followed by female-male 3.09, female-juvenile 2.2 and female-female 1.6. Eating was non-significantly $(\mathrm{p}=0.46)$ higher. In female-juvenile the mean 2.80 was the highest followed by female-male 2.36 , female-female 2.2 and female-infant 1.8 . Conciliation was non-significantly $(\mathrm{p}=0.11)$ higher in dominance. The highest mean observed 2.54 was for female-male followed by female-juvenile 2.3, female-female 2.1 and female infant 0.87 . Approaching behavior was shown non-significantly $(\mathrm{p}=0.83)$ higher. The highest mean observed 2.63 was for female-male, followed by female-female and female-juvenile 2.3 and finally by female-infant 2.12. Biting evaluated significantly $(\mathrm{p}<0.05)$ higher in female-female with mean of 1.3 . Sexual behavior was significantly $(p<0.05)$ higher in dominance female and male with mean of 1.36 . Submissive behavior found significantly $(\mathrm{p}<0.01)$ higher. The female-female category showed the highest mean 3 , followed by female-infant 2.12 , female-juvenile 1.5 and female-male 1 . Baby caring was calculated significantly $(\mathrm{p}<0.01)$ higher in dominance. The highest mean observed 2.62 was for female-infant, followed by female-female 0.3 , female-male 0.27 and for female-juvenile it appeared to be null (Table 3).

\section{Discussion}

\subsection{Social organization (Group Organization)}

Alpha and Beta Male:

It was revealed that the alpha males showed significant dominance for the behaviours of fighting, sex, shaking branches, moving, grooming received, attacking and protection as compared to the beta males. The findings of this study pointed out that the dominant males exhibit the property to mating, more frequently than subordinate 
males. These findings agree with the finding for troops of baboons DeVore and Hall (1965), Furthermore, as pointed out in previous study that dominant male provide better sexual satisfactions than lower ranking male (Angst, 1975), thus the mating activity of the alpha male is higher (Table, 1).

\subsection{Social Relationship of Males}

For the social relations, it appeared that the means for the behaviours of grooming, submission and approach were the most pronounced for the male-male case, these findings agrees with Kummer's et al. (1974) study as described that a new relationship between two males always initiates with fighting. The initial incidence of "grooming" is usually to settle the new relationship. Kummer et al. (1974) concluded that "fighting" depicts less "compatibility" between the individuals and "grooming" depicts higher degree of "compatibility". Further more, male bonnet macaques possess high conciliatory tendency and usually groom and aid one another (Cooper and Bernstein 2008).

In case of aggression the value of mean was more for the male-infant case, followed by the male-juvenile case. Previous studies suggest that usually during a movement in the wild, adult males at the front of the movement probably protect juveniles from predators (Boinski et al. 2000); Because of this reason the adult males are more aggressive toward infants and juveniles. The reconciliation behaviour was found the highest for the male-female case, studies suggest that an alpha female holds a special position in the group and possibly influences the male dominance ranks to some extent (Nakamichi et al. 1995). Furthermore, studies have shown that the chances of an increase female's proximity to a new alpha male are higher (Nakamichi et al. 1995), observations describe that proximity scores of adult females and defeated previous alpha male's decreases after the male's defeat. Thus the reconciliation between a male and a female might be high, as shown in Table 2.

\subsection{Social relationship of Females}

In natural conditions a female's spatial position and her predation risk is affected by her dominance rank, for example as described by Van Noordwujk and Van Schaik (1987), for Macaca fasciculari. In primates, despotic dominance hierarchies among females are frequently accompanied by nepotistic ranking systems as depicted by Sterck and Steenbeek (1997). If the females lack a nepotistic rank system, it is often complicated to distinguish dominance ranks and the female ranks tend to be unstable over a female's usual life (Sterck and Steenbeek 1997). In present study the dominance of the female's behaviour with other members of the group was observed. It was found that for biting and submission mean were the highest for female-female case. This study agree with Gouzoules (1980) who reported that a middle ranking female Japanese monkey outranked the alpha female with the support of the alpha male. After her establishment in the alpha-position the other females having alliance with her rose in rank as well. The possible reasons for submission are many, but they could be indirectly influenced by high ranking males. However, the males apparently rather play passive role in the fights, as was also observed by Ehardt and Bernstein (1986). On the other hand Ehardt and Bernstein (1986) also reported severe facial tissue and muscle damage and extremities of rhesus monkeys during a female overthrow, this shows why biting is the highest in the female-female case. Although, the means for conciliation, sex and approach were the highest for the female-male case and eating was the highest in the female-juvenile case. However, grooming and caring of the baby were the highest for the female-infant case (Table, 3 ).

\subsection{Mating system of Macaca fascicularis}

This study indicates that the mating system of Macaca fascicularis is polygamy and polyandry (Table, 3 ). The mating system of the long tailed macaques pointed out that a group is structured in relation to sexual behavior with other member of the same group; furthermore this system depends upon the background of the group. With respect to these animals, it indicates that both males and females mate with multiple partners, suggesting that mating is promiscuous. Annika et al. (2004) described that in the mating system of primates most of the sexual interaction was conducted by alpha and beta males even when females mated with several males, it seems that not only male monopolization but as well as the female sexual co-operation also favors high-ranking males in long-tailed macaques, thus sexual behavior was the most predominant in the alpha and beta males in this species (Table, 1). These results agree with the study of Antje et al. (2006).

\subsection{Polygamy and Polyandry in Macaca fascicularis}

Male of Macaca fascicularis groom females most of the time in the same group for sex. Male exhibits aggressive behaviors during sex and attack on the other member of the group. Dominant male's exhibit increased approach during sexual activity as compared to the other males. On the other hand reconciliation was found to be higher in male female case (Table, 2). In small "family" groups of hamadryas baboons based on one adult male and one to three adult females and their young, the males mate exclusively with their own females and inter-male 
competition over females never takes place. The male of such families also adopt or abduct the juvenile females while still immature and kept until they are old enough to mate (Larissa and Steven, 2006). It is depicted that males prefer high-ranking females as mating partners which is a common finding in primates (Kuester and Paul 1996), since the higher-ranking females usually exhibit a higher lifetime reproductive success than lower-ranking females in case of long-tailed macaques (Van Schaik et al., 1999). In another study Hodges et al. (2006) described that females are not willing to mate with other males during the time they were in consort with the alpha male. However, at the base level females do not show any mate preference concerning male rank or residency. The female long-tailed macaques most frequently mated any available males during the fertile phase (Nikitopoulos et al., 2005). Thus it seems that there is a low degree of female mate choice in long-tailed macaques, not only due to barriers set by the males but also to a lack of choosiness in the females. Furthermore the females seem to aim at mating with several males, possibly to receive the benefits of polyandrous mating and sperm competition (Wolff and Macdonald, 2004). While the females cooperate with the dominant male when he is interested in them and adopts polyandrous mating when he is not interested. It is also found that higher-ranking females exhibit more sexual behavior and become reproductively mature before lower-ranking females. The offspring of these higher-ranking females have a greater chance of survival than others. Both of these phenomena are related to the greater food availability and decreased amount of aggression experienced by the higher ranking females. As in all primates, there is an extended period of juvenile dependence. Females provide the bulk of the care for offspring. The young receive nourishment, encouragement, grooming, protection, and teaching from the mother (Table 3). Young females are likely to remain in the troop into which they were born, whereas males are likely to emigrate at or near sexual maturity. While, the choice of the female may be an important factor in deciding the mating strategy, although there is no evidence that females positively choose high-ranking males as potential sires of their offspring. However, as a mating strategy, it may be advantageous for a female to copulate more frequently with a high-ranking male, who could offer greater protection for their offspring. In the hamadryas baboons the number of males with whom each female copulates varies. However, highest-ranking male in the group often manages to exclude the other males from his female. Furthermore it has been found that the females exhibit sexual presentations to multiple males, copulate with multiple males, to confuse paternity among males, which may in turn provide protection of the infants by multiple males (Dixson 1998; Soltis et al., 2001).

\section{Conclusion}

Present study is providing comparative data on male and female long tailed macaques by describing details of male and female social relationships as well as dominance style of alpha and beta male. The results indicate 1) that male long tailed macaques are tolerant than previously predicted based on most behavioral traits investigated and 2) that males and females differ in their social style. Both findings are in line with prediction based on socioecological reasoning in light of sex-differential resource characteristics.

\section{Aknowledgements}

I would like to acknowledge the great contribution of Associate Professor Dr. Sahahrul Anuar my supervisor at School of Biological Sciences Universiti Sains Malaysia for helping me in conducting this study. I would also like to forward my appreciation to the Department Of Wildlife and National Parks, Pulau Pinang for cooperation and data collection in Botanical Gardens Penang, special thanks to Mr. Ganesh and driver Mr. Soma School of biological sciences for providing guidance and assistance in 'Gardens' during data collection, and at the end I would like to thank School of Biological Sciences Universiti Sains Malaysia for their facilitation.

\section{References}

Angst, W. (1975). Basic data and concepts on the social organization of Macaca fascicularis. Primate behavior, 4, 325-388.

Annika, T. H., Keeley \& Brain, W. (2004). The mating system of tadarida Brasiliensis (Chiroptera: Molossidae) in a large highway bridge colony. Journal of Mammalogy, 85(1), 113-119.

Antje, E., Michael, H., Hodges, J. K., Peter, N. \& Carsten, N. (2006). Determinants of male reproductive success in wild long-tailed macaques (Macaca fascicularis)-male monopolisation, female mate choice or post-copulatory mechanisms. Behavavioral Ecology and Sociobiology, 59(6), 740-752.

Aureli, F. (1992). Post-conflict behavior among wild long-tailed macaques (Macaca fascicularis). Behavioral Ecology and Sociobiology, 31(5), 329-337.

Bernstein, I.S. (1974). Principles of primate group organization. In Chiarelli, A.B. (ed.), Advances in behavioral biology 9. New York, Plenum Press, 283-298. 
Boinski, S., Treves, A. \& Chapman, C. A. (2000). A critical evaluation of the influence of predators on Primates: Effects on group travel. In S. Boinski, \& P. A. Garber (Eds.), On the move Chicago: University of Chicago Press, 43-72.

Cooper, M. A. \& Bernstein, I. S. (2008). Evaluating Dominance Styles in Assamese and Rhesus Macaques. International journal of primatology, 29(1), 225-243.

David, A. H. (1986). Social Relationships Between Adult Male and Immature Rhesus Macaques. Primates, 27(4), 425-440.

DeVore \& HALL, K. R. L. (1965). Baboon ecology. In:Primate Behavior: Field Studies of Monkeys and Apes,I. DeVore (ed.), Primate Behavior, 20 - 53.

Dixson AF. 1998. Primate sexuality. Oxford: Oxford University Press. 546p.

Ehardt, C. L. \& Bernstein, L. S. (1986). Matrilineal overthrows in rhesus monkey groups. International Journal of Primatololgy, (7), 157-181.

Filippo, A. (1997). Post-Conflict Anxiety in Nonhuman Primates: The Mediating Role of Emotion in Conflict Resolution. Aggressive Behavior, 23, 315-328.

Gouzoules, H. (1980). The alpha female: Observations on captive pigtail monkeys. Folia Primatologica, 33, $46-56$.

Gray, G. E. (1986). Japanese Macaques (Macaca fuscata) Social Development: Sex Differences in Juvenile Behavior. Primates, 27(2), 141-150.

Heymann, E. W., Encarnación, C. F. \& Canaquín, Y. J. E. (2002). Primates of the Río Curaray, northern Peruvian Amazon. Int. J. Primatol, 23(1), 191-201.

Heywood, V. H. (1991). Developing a strategy for germplasm conservation in botanic gardens. Their Role in Conservation an Development. Academic Press Limited, London. Tropical Botanic Gardens, 11-23.

Hodges, J. K., Antje, E., Michael, H., Peter, N. \& Carsten, N. (2006). Determinants of male reproductive success in wild long-tailed macaques (Macaca fascicularis)-male monopolisation, female mate choice or post-copulatory mechanisms. Behavioral Ecology Sociobioogyl, 59, 740-752.

Izard, M. K. \& Smith, D. G. (2000). Reproduction in Indonesian vs. Indochinese cynomolgus macaques revisited. American Journal of Primatololgy, 51(1), 63-64.

Janson, C. H., \& van Schaik, C. P. (1993). Ecological risk aversion in juvenile primates: Slow And steady wins the race. In Pereira, M. E., \& Fairbanks, L. A. (eds.), Juvenile Primates: Life History, Development, and Behavior, Oxford University Press, New York, pp. 57-74.

Kuester, J. \& Paul, A. (1996). Female-female competition and male mate choice in Barbary macaques (Macaca sylvanus). Behaviour, 133 (9/10), 763-790.

Kummer, H., Goetz, W. \& Angst, W. (1974). Triadic differentiation: An inhibitory process protecting pair bonds in baboons. Behaviour, 49(1), 62-87.

Larissa, S. \& Steven, R. L. (2006). Perspectives on Reproduction and Life history in Baboons. Biomedical and Life Sciences. Evolutionary Primatology, Developments in Primatology: Progress and Prospects, 1- 15.

Marjolijn, Das., Zsuzsa, Penke., Jan, A. R. A. M. \& van, Hooff. (1998). Postconflict Affiliation and Stress-Related Behavior of Long-Tailed Macaque Aggressors. International Journal of Primatology, 19(1), 53 71.

Nakamichi, M., Kojima, Y., Itoigawa, S., Imakawa, S. \& Machida, S. (1995). Interactions among adult males and females before and after the death of the alpha male in a free ranging troop of Japanese macaques. Primates, 36(3), 385-396.

Nikitopoulos, E., Heistermann, M., de Vries, H., van Hooff, J. A. R. A. M. \& Sterck, E. H. M. (2005). A pair choice test to identify female mating pattern relative to ovulation in long-tailed macaques, Macaca fascicularis. Animal Behavior, 70(6), 1283-1296.

Nobuyuki K \& Tim H. C (2010). Grooming and the value of social relationships in cooperatively breeding meerkats. Animal Behaviour, 79, 271-27.

Nozaki, M. (2009). Grandmothers care for orphans in provisioned troop of Japanese macaques (Macaca fuscata). The University of Tokyo, Japan, Primates, 50(1), 85-88. 
Oommen, M. A. \& Shanker, K. (2008). Ecology and Behaviour of an Endemic Treeshrew Tupaia Nicobarica Zelebor 1869 on Great Nicobar Island. India Journal of the Bombay Natural History Society, 105(1), 55-63.

Soltis, J. \& Richard, M. (2001). Can Females Gain Extra Paternal Investment by Mating with Multiple Males? A Game Theoretic Approach the American naturalist, 158 (5), 519-529. http://xcelab.net/rmpubs/femalesAN 2001.pdf.

Sterck, E. H. M. \& Steenbeek, R. (1997). Female dominance relationships and food competition in the sympatric Thomas langur and long-tailed macaque. Behaviour, 134(9/10), 749-774.

Thierry, B. (1986). A comparative study of aggression and response to aggression in three species of macaque. In Else, J.G. \& Lee, P.C. (eds.), Cabridge University press, Primate Ontogeny, Cognition, and Social Behaviour, 307-313.

Thierry, B. (1990). Feedback loop between kinship and dominance: The macaque model. J. Theoret. Biol., 145, 511-521.

Van Noordwijk, M. A. \& van, Schaik, C. P. (1987). Competition among female long-tailed macaques, Macaca fascicularis. Trumpington Street, Cambridge University press, UK, Animal Behavior, 35(2), 89-577.

Van Noordwijk, M. A., Hemelrijk, C. K., Herremans, L. A. M. \& Sterck, E. H. M. (1993). The socioecology of juvenile long-tailed macaques, Macaca fascicularis. In M. E. Pereira, \& L. A. Fairbanks (Eds.) Juvenile primates: Life history, development, and behavior (pp. 77-85). New York: Oxford University Press.

Van Schaik, C. P., van Noordwijk, M. A. \& Nunn, C. L. (1999). Sex and social evolution in primates. In: Lee PC (ed). Cambridge University Press, Comparative primate socioecology, 204 - 231.

Van Schaik, C. P., Van Noordwijk, M. A., de Boer, R. J. \& Den Tonkelaar, I. (1983). The effect of group size on time budgets and social behaviour in wild long-tailed macaques (Macaca fascicularis). Behavioral Ecology and Sociobiology, 13 (3), 173-181.

Wolff, J. O. \& Macdonald, D. W. (2004). Promiscuous females protect their offspring. Trends Ecology and Evolution, 19(3), 127 - 134. 
Table 1. Comparison of dominant behavior between alpha and beta male

\begin{tabular}{|c|c|c|c|c|c|}
\hline Dominance & Numbers & Behaviors & Mean & Std. Deviation & p-value* \\
\hline Alpha male & 35 & \multirow{2}{*}{ Fighting } & 2.23 & 1.352 & \multirow[t]{2}{*}{0.026} \\
\hline Beta male & 18 & & 1.39 & 1.195 & \\
\hline Alpha male & 35 & \multirow{2}{*}{ Sex } & 1.29 & 1.100 & \multirow{2}{*}{0.741} \\
\hline Beta male & 18 & & 1.17 & 1.465 & \\
\hline Alpha male & 35 & \multirow{2}{*}{ Eating } & 2.03 & 1.248 & \multirow{2}{*}{0.002} \\
\hline Beta male & 18 & & 0.83 & 1.200 & \\
\hline Alpha male & 35 & \multirow{2}{*}{ Shaking branches } & 1.91 & 1.755 & \multirow{2}{*}{0.961} \\
\hline Beta male & 18 & & 1.89 & 1.875 & \\
\hline Alpha male & 35 & \multirow{2}{*}{ Moving } & 1.60 & 1.168 & \multirow{2}{*}{0.536} \\
\hline Beta male & 18 & & 1.83 & 1.505 & \\
\hline Alpha male & 35 & \multirow{2}{*}{$\begin{array}{l}\text { Grooming } \\
\text { received }\end{array}$} & 0.91 & 0.981 & \multirow{2}{*}{0.006} \\
\hline Beta male & 18 & & 0.33 & 0.485 & \\
\hline Alpha male & 35 & \multirow{2}{*}{$\begin{array}{l}\text { Grooming } \\
\text { Given }\end{array}$} & 0.94 & 1.083 & \multirow{2}{*}{0.051} \\
\hline Beta male & 18 & & 2.00 & 2.765 & \\
\hline Alpha male & 35 & \multirow{2}{*}{ Attacking } & 1.06 & 1.282 & \multirow{2}{*}{0.025} \\
\hline Beta male & 18 & & 2.17 & 1.757 & \\
\hline Alpha male & 35 & \multirow{2}{*}{ Protection } & 1.97 & 1.465 & \multirow{2}{*}{0.125} \\
\hline Beta male & 18 & & 2.72 & 1.994 & \\
\hline Alpha male & 35 & \multirow{2}{*}{ Facial threat } & 1.06 & 1.259 & \multirow{2}{*}{0.275} \\
\hline Beta male & 18 & & 0.67 & 1.138 & \\
\hline
\end{tabular}

*t-test

Table 2. Male social relationship with other members of the group

\begin{tabular}{lccccc}
\hline Age/sex & Numbers & Behaviors & Mean & Std. Deviation & P-Value* \\
\hline Male-female & 8 & & 1.25 & 1.488 & \\
Male-male & 15 & \multirow{2}{*}{ Grooming } & 2.07 & 1.223 & 0.504 \\
Male-juvenile & 14 & & 1.71 & 1.490 & \\
Male-infant & 10 & & 1.40 & 1.350 & \\
\hline Male-female & 8 & & 1.88 & 1.126 & \\
Male-male & 15 & \multirow{2}{*}{ Aggression } & 2.40 & 0.986 & \\
Male-juvenile & 14 & & 2.64 & 1.082 & \\
Male-infant & 10 & & 3.30 & 0.675 & \\
\hline Male-female & 8 & & 2.38 & 1.506 & \\
Male-male & 15 & Submission & 2.53 & 1.598 & \\
Male-juvenile & 14 & & 2.36 & 1.946 & \\
Male-infant & 10 & & 1.40 & 1.713 & \\
\hline Male-female & 8 & & 2.75 & 1.282 & \\
Male-male & 15 & \multirow{2}{*}{ Approach } & 4.73 & 1.223 & \\
Male-juvenile & 14 & & 3.14 & 1.406 & \\
Male-infant & 10 & & 3.90 & 0.994 & \\
\hline Male-female & 8 & & 6.75 & 1.035 & \\
Male-male & 15 & \multirow{2}{*}{ Reconciliation } & 3.27 & 2.712 & \\
Male-juvenile & 14 & & 5.07 & 2.336 & \\
Male-infant & 10 & & 5.00 & 2.211 & \\
\hline
\end{tabular}

*One-way ANOVA 
Table 3. Mating system and female social relationship with other members

\begin{tabular}{|c|c|c|c|c|c|}
\hline Variables & Numbers & Behaviors & Mean & Std deviation & P-value* \\
\hline Female-female & 10 & \multirow{4}{*}{ Aggression } & 2.1000 & 1.19722 & \multirow{4}{*}{0.239} \\
\hline Female-male & 11 & & 1.2727 & 0.78625 & \\
\hline Female-juvenile & 10 & & 2.3000 & 1.82878 & \\
\hline Female-infant & 8 & & 1.7500 & 0.46291 & \\
\hline Female-female & 10 & \multirow{4}{*}{ Grooming } & 1.6000 & 1.83787 & \multirow{4}{*}{0.012} \\
\hline Female-male & 11 & & 3.0909 & 1.04447 & \\
\hline Female-juvenile & 10 & & 2.2000 & 1.22927 & \\
\hline Female-infant & 8 & & 3.7500 & 1.38873 & \\
\hline Female-female & 10 & \multirow{4}{*}{ Eating } & 2.2000 & 1.54919 & \multirow{4}{*}{0.469} \\
\hline Female-male & 11 & & 2.3636 & 0.92442 & \\
\hline Female-juvenile & 10 & & 2.8000 & 1.39841 & \\
\hline Female-infant & 8 & & 1.8750 & 0.99103 & \\
\hline Female-female & 10 & \multirow{4}{*}{ Conciliation } & 2.1000 & 1.44914 & \multirow{4}{*}{0.114} \\
\hline Female-male & 11 & & 2.5455 & 1.57249 & \\
\hline Female-juvenile & 10 & & 2.3000 & 1.33749 & \\
\hline Female-infant & 8 & & 0.8750 & 1.64208 & \\
\hline Female-female & 10 & \multirow{4}{*}{ Approach } & 2.3000 & 1.41814 & \multirow{4}{*}{0.837} \\
\hline Female-male & 11 & & 2.6364 & 1.12006 & \\
\hline Female-juvenile & 10 & & 2.3000 & 0.82327 & \\
\hline Female-infant & 8 & & 2.1250 & 1.64208 & \\
\hline Female-female & 10 & \multirow{4}{*}{ Biting } & 1.3000 & 0.94868 & \multirow{4}{*}{0.016} \\
\hline Female-male & 11 & & 0.4545 & 1.21356 & \\
\hline Female-juvenile & 10 & & 0.8000 & 0.42164 & \\
\hline Female-infant & 8 & & 0.0000 & 0.0000 & \\
\hline Female-female & 10 & \multirow{4}{*}{ Sex } & 0.1000 & 0.31623 & \multirow{4}{*}{0.031} \\
\hline Female-male & 11 & & 1.3636 & 1.28629 & \\
\hline Female-juvenile & 10 & & 0.8000 & 1.68655 & \\
\hline Female-infant & 8 & & 0.0000 & 0.0000 & \\
\hline Female-female & 10 & \multirow{4}{*}{ Submission } & 3.0000 & 1.56347 & \multirow{4}{*}{0.004} \\
\hline Female-male & 11 & & 1.0000 & 1.26491 & \\
\hline Female-juvenile & 10 & & 1.5000 & 0.97183 & \\
\hline Female-infant & 8 & & 2.1250 & 0.83452 & \\
\hline Female-female & 10 & \multirow{4}{*}{ Baby care } & 0.3000 & 0.94868 & \multirow{4}{*}{$<0.01$} \\
\hline Female-male & 11 & & 0.2727 & 0.90453 & \\
\hline Female-juvenile & 10 & & 0.0000 & 0.0000 & \\
\hline Female-infant & 8 & & 2.6250 & 1.84681 & \\
\hline
\end{tabular}

\footnotetext{
*One-way ANOVA
}

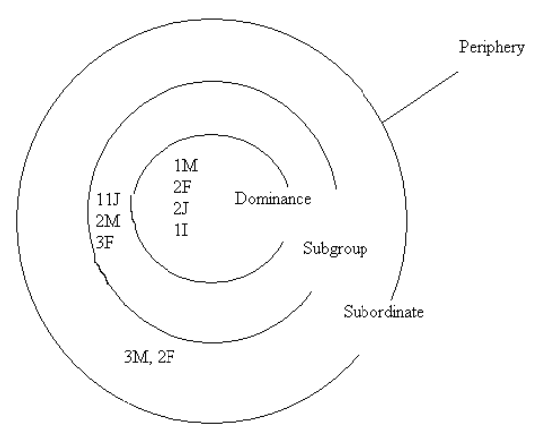

Figure 1. Composition of a group of Macaca fascicularis in Botanical Gardens 